\section{A DENTAL CHAIR THAT'S RIGHT FOR YOU}

A-dec are proud to be supporting the BDA Live Demonstration Theatre and also look forward to welcoming you to stand B70 at this year's British Dental Conference and Exhibition.

On stand B70 the A-dec team will be showcasing the stylish top-of-the-range A-dec 500 dental chair with Red Dot award winning A-dec LED light. Join them at the show to see if there is an A-dec dental chair for you. After all, you could spend over 26,565 hours with your chair throughout your career so it needs to be right for you and your dental team.

A-dec territory managers will be on stand for the duration of the show offering advice on treatment room design and ergonomic solutions for your practice.

Visit stand B70 or call 0800233285 for more information.

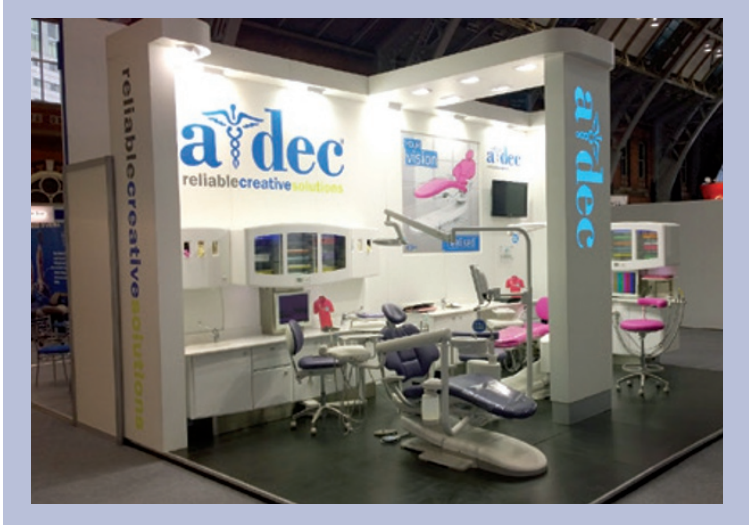

\section{HELPING TO DELIVER ADVANCED ORAL CARE}

Johnson \& Johnson Ltd, the makers of LISTERINE ${ }^{\circledR}$, are proud to be gold sponsors at the British Dental Conference \&t Exhibition. LISTERINE ${ }^{\circledR}$ Advanced Defence Gum Treatment is a twice-daily mouthwash clinically proven to treat gum disease as an adjunct to mechanical cleaning and to offer an alternative to chlorhexidine-based remedies.

It is formulated with unique LAE (ethyl lauroyl arginate) technology that forms a physical coating on the pellicle to prevent bacteria attaching, and so interrupts biofilm formation.

Designed to help you treat and/or prevent specific oral care conditions, this range also includes LISTERINE $^{\circledR}$ Advanced Defence Sensitive and LISTERINE ${ }^{\circledR}$ Advanced Defence Cavity Guard.

With this range of expert daily mouthwashes, Johnson \& Johnson is looking forward to working more closely with dental professionals to help deliver advanced treatment outcomes for patients, for expert care when you're not there.

For information on the LISTERINE ${ }^{\circledR}$ Advanced Defence range, visit stand C20 to speak to a member of the LISTERINE ${ }^{\circledR}$ Professional team.

\section{TEST DRIVE A TOOTHBRUSH}

Oral-B has recently introduced its Test Drive trial programme, which allows multiple users to experience Oral-B power and toothpaste using a shared handle in a hygienic way. Dental professionals will now be able to evaluate the product themselves before recommending it to patients. Patients will also be able to experience the product before investing in the technology.

The new Oral-B SmartSeries electric toothbrush with Bluetooth 4.0 connectivity is another recent innovation. The new toothbrush connects to the Oral-B App, recording brushing activity which patients can then share with their dental professional. Brushing duration, mode and problem zones can all be highlighted and the information easily retrieved.

The mechanical benefits of OralB's power toothbrushes compliment the chemical efficacy afforded by their Pro-Expert toothpaste. Gum health through effective plaque control is just one of the many beneficial features of Oral-B's Pro-Expert toothpaste and it's the inclusion of stabilised stannous fluoride that makes the difference.

Visitors to the British Dental Conference and Exhibition are also encouraged to log onto Oral-B's professional website, www.dentalcare.com.

\title{
MAKE YOUR MARK WITH FACIAL AESTHETICS
}

If you want to make your mark in the rapidly expanding and lucrative world of facial aesthetics, Derma Medical can help. Their new bespoke and unique cosmetic training courses provide the latest in 21st century techniques.

The combined one-day Foundation \& Advanced Botox and Dermal Fillers courses will equip you with the knowledge and skills required to carry out the latest and most commonly requested facial aesthetic injectable treatments. With vastly growing numbers of nonsurgical cosmetic injectable procedures and advances in cosmetic dentistry, the courses provide excellent opportunities for dentists keen on expanding their clinical skills.

Derma Medical are also affiliated with recruitment companies, so upon completion of your training you can be directed towards

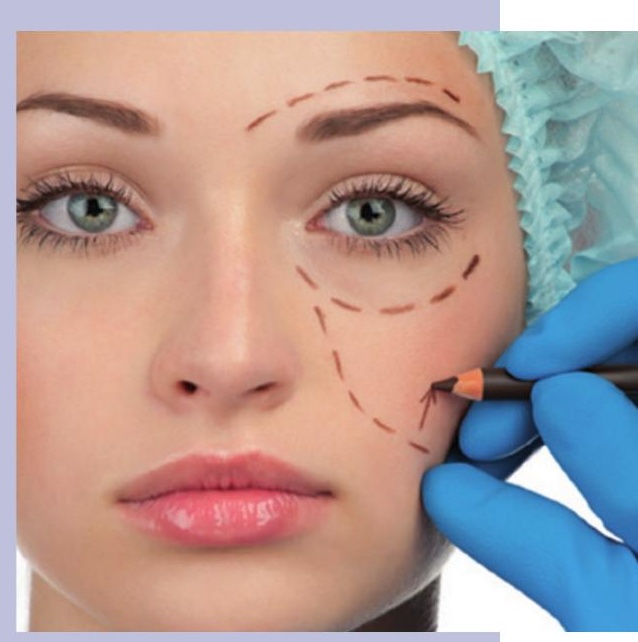

employment within the cosmetic industry. All courses are CPD accredited and Hamilton \& Fraser cosmetically insured. The next courses take place on 9 and 10 May 2015 at the Royal College of General Practitioners in London.

Visit www.dermamedical. co.uk oremailinfo@dermamedical.co.uk for more information.

\section{ARE YOU PLANNING YOUR EXIT?}

Come and meet the Dental Elite team at the 2015 British Dental Conference and Exhibition on stand B36 or join us after the show on Thursday 7 May at the Dental Elite Exit Seminar on dental practice and exit planning at the Midland Hotel directly opposite the GMEX.

The drinks reception with canapés will begin at $6 \mathrm{pm}$, followed by the seminar. For more information visit www.dentalelite.co.uk, email info@dentalelite.co.uk or call 01788545900. 